\title{
Wilt of Perilla Caused by Fusarium spp.
}

\author{
Woo Sik Kim, Wan Gyu Kim ${ }^{1 *}$, Weon Dae Cho and Seung Hun $\mathbf{Y u}^{2}$ \\ Plant Pathology Division, National Institute of Agricultural Science and Technology, Rural Development Administration (RDA), \\ Suwon 441-707, Korea \\ 'Applied Microbiology Division, National Institute of Agricultural Science and Technology, RDA, Suwon 441-707, Korea \\ 'Division of Applied Biology, Chemistry and Food Science, Chungnam National University, Daejeon 305-764, Korea
}

(Received on September 9, 2002)

\begin{abstract}
A survey of Fusarium wilt of perilla was conducted in 12 locations in Korea from 1999 to 2001. The disease occurred in 74 out of 187 fields in the 12 locations surveyed, and incidence of the disease reached up to $30 \%$ at its maximum in some perilla fields in Seosan and Dangjin. Incidence of the disease in the other locations ranged from 0.2 to $20 \%$. A total of 327 isolates of Fusarium spp. were obtained from stems and roots of the diseased perilla plants. The isolates were identified based on their morphological characteristics. Out of the 327 isolates of Fusarium, 277 isolates from 12 locations were identified as $F$. oxysporum, 11 isolates from three locations as $F$. solani, 17 isolates from two locations as $F$. equiseti, 4 isolates from one location as $F$. avenaceum, and 6 isolates from one location as $F$. subglutinans. The other 12 isolates of Fusarium from four locations were unidentified. Twelve isolates of $F$. oxysporum and two isolates each of the other Fusarium spp. were tested for their pathogenicity to five cultivars of perilla. Seven isolates of $F$. oxysporum were strongly pathogenic to some perilla cultivars, but the other five isolates were weakly or not pathogenic. One isolate of $F$. solani was strongly pathogenic to all the perilla cultivars tested, but another isolate was not pathogenic. All the isolates of $F$. equiseti, $F$. avenaceum, and $F$. subglutinans tested were not pathogenic to any of the perilla cultivars tested. Symptoms on the perilla plants induced by artificial inoculation with strongly pathogenic isolates of $F$. oxysporum and $F$. solani appeared as wilt, stem blight, and root rot, which were similar to those observed in the fields. The isolates which induced symptoms by artificial inoculation were re-isolated from the lesions of the perilla plants inoculated. All the isolates of $F$. oxysporum tested were not pathogenic to eight other crops inoculated. Results of this study reveal that $F$. oxysporum is the main pathogen of perilla wilt and that it is host specific to perilla. A forma specialis of $F$. oxysporum causing wilt of perilla is proposed as perillae.
\end{abstract}

\footnotetext{
*Corresponding author.

Phone) +82-31-290-0393, FAX) +82-31-290-0399

E-mail)wgkim@rda.go.kr
}

Keywords : Fusarium avenaceum, F. equiseti, F. oxysporum, F. solani, F. subglutinans, pathogenicity, perilla, wilt.

Perilla [Perilla frutescens (L.) Britton var. japonica (Hassk.) Hara] is grown as an oil crop in east Asian countries. The plant is also grown as a vegetable crop under greenhouse conditions in Korea. Growers usually cultivate perilla in open fields to harvest seeds for oil production during summer. During a disease survey of perilla in several locations in Korea, severe outbreaks of wilted plants were sometimes observed. The diseased plants showed rot symptoms on basal parts of stems and roots. Fusarium spp. was consistently isolated from the diseased plant parts, which suggested that the fungi are associated with the disease.

It has been reported that Fusarium spp. is widely distributed in the soil and mostly cause wilt on a variety of plants (Armstrong and Armstrong, 1975; Booth, 1971; Snyder and Hansen, 1940). However, there have been no reports on wilt of perilla caused by Fusarium spp. except a listed record on stem rot of perilla caused by an unknown species of Fusarium (Anonymous, 1998). This study was conducted to investigate the occurrence of perilla wilt in Korea and to determine the etiological characteristics of the causal Fusarium spp.

\section{Materials and Methods}

Survey and collection of diseased plants. Perilla fields in 12 locations in Korea were surveyed in July through October from 1999 to 2001 . Perilla plants with wilt symptoms were collected, and the lesions were anatomically examined.

Isolation of pathogens. Lesion pieces $(3-5 \mathrm{~mm})$ cut from the diseased plants of perilla were plated on $2 \%$ water agar medium (WA) after surface-sterilizing with $1 \%$ sodium hypochlorite solution for 1 minute. Fungal isolates obtained from the lesion pieces were transferred to potato dextrose agar (PDA) slants. Isolates of Fusarium spp. identified by morphological observation under a light microscope were cultured for sporulation on PDA at $25 \%$ for 10-20 days. Using an inoculating needle, conidia 
produced on PDA were suspended in $200 \mu \mathrm{l}$ of sterile distilled water in a $1.5 \mathrm{ml}$ microtube to make a conidial suspension. A loopful of the conidial suspension was streaked on the WA surface with a platinum wire loop to distribute the conidia. After $12-20 \mathrm{~h}$ incubation at $25 \%$, agar fragments bearing a single germinated conidium were transferred to fresh WA and incubated at $25 \%$ for 5 days. Single-conidium isolates obtained from the WA plates were cultured on PDA and used for the identification and pathogenicity tests.

Investigation of morphological characteristics. Each isolate was cultured on carnation leaf agar (Fisher et al., 1982) at $27 \%$ for 20-30 days in alternating cycles of $12 \mathrm{~h}$ NUV light and $12 \mathrm{~h}$ darkness. The morphological features of each culture on the medium were examined by light microscope. Fifty conidia, conidiophores, and chlamydospores chosen randomly from each culture were observed and measured under the light microscope. Pathogenicity test. Seeds of five cultivars of perilla and two cultivars each of eight other crops were sown in circular plastic pots $(21 \mathrm{~cm}$ in diameter and $29 \mathrm{~cm}$ in height) containing sterile soil, and the pots were placed in a greenhouse at $18-32 \%$. Twentythree- to 25-day-old plants of perilla and other crops were used for the pathogenicity tests. Twelve isolates of $F$. oxysporum and two isolates each of the other Fusarium spp. were tested for their pathogenicity to the five cultivars of perilla. The 12 isolates of $F$. oxysporum were also tested for their pathogenicity to two cultivars each of eight other crops.

Each isolate of Fusarium species was cultured on cornmealsand medium ( $23 \mathrm{~g}$ cornmeal: $210 \mathrm{~g}$ sand: $40 \mathrm{ml}$ distilled water) in $500 \mathrm{ml}$-flasks for 30-40 days to prepare the inoculum. For the inoculation tests, surface soil around the plant was dug at a depth of 2-3 cm, and $50 \mathrm{~g}$ of each inoculum was placed on the roots. The inoculated plant parts were covered with the original soil. The same quantity of cornmeal-sand medium was used for the control plant. The inoculated and control plants were cultivated in the greenhouse at $18-32^{\circ} \mathrm{C}$. The inoculation experiment was performed in three replicates. Symptoms were observed during cultivation of the inoculated plants, and disease rating was made
Table 1. Occurrence of Fusarium wilt of perilla in 12 locations in Korea from 1999 to 2001

\begin{tabular}{lccc}
\hline \hline Location & $\begin{array}{c}\text { No. of fields } \\
\text { surveyed }\end{array}$ & $\begin{array}{c}\text { No. of fields } \\
\text { infected }\end{array}$ & $\begin{array}{c}\% \text { infected } \\
\text { plants }^{\mathrm{a}}\end{array}$ \\
\hline Cheongyang & 20 & 8 & $0.2-10.0$ \\
Dangjin & 20 & 7 & $0.7-30.0$ \\
Geumsan & 21 & 9 & $0.2-5.0$ \\
Hongcheon & 14 & 4 & $0.2-15.0$ \\
Hwacheon & 12 & 3 & $0.2-5.0$ \\
Inje & 11 & 2 & $0.3-5.0$ \\
Namwon & 13 & 6 & $0.2-10.0$ \\
Sancheong & 11 & 7 & $0.3-20.0$ \\
Seosan & 22 & 8 & $0.6-30.0$ \\
Suwon & 13 & 9 & $0.3-10.0$ \\
Yangpyeong & 11 & 7 & $0.2-10.0$ \\
Yeoju & 19 & 4 & $0.2-5.0$ \\
\hline Total & 187 & 74 & $0.2-30.0$ \\
\hline
\end{tabular}

${ }^{a}$ One hundred plants in each field were investigated in three to five replicates.

based on the severity of wilting and rotting induced on the plants 30 days after inoculation. Re-isolation of the pathogen from the lesions on the plants was conducted as described previously.

\section{Results}

Disease incidence and symptoms. Wilt of perilla occurred in 74 out of 187 fields in 12 locations surveyed in Korea, and the disease incidence reached up to $30 \%$ at its maximum in some perilla fields in Seosan and Dangjin (Table 1). The disease incidence in the other locations ranged from 0.2 to $20 \%$. Symptoms appeared as wilt after the mid growing stage of perilla in the fields (Fig. 1). Diseased plants were somewhat retarded in their growth in

Table 2. Morphological characteristics of Fusarium spp. isolates from perilla plants ${ }^{2}$

\begin{tabular}{|c|c|c|c|c|}
\hline \multirow{2}{*}{ Species } & \multirow{2}{*}{$\begin{array}{l}\text { Shape and size }(\mu \mathrm{m}) \text { of } \\
\text { conidiophores }\end{array}$} & \multicolumn{2}{|c|}{ Shape and size $(\mu \mathrm{m})$ of } & \multirow{2}{*}{$\begin{array}{c}\text { Shape and diameter }(\mu \mathrm{m}) \\
\text { of chlamydospores }\end{array}$} \\
\hline & & Microconidia & Macroconidia & \\
\hline Fusarium oxysporum & $\begin{array}{l}\text { Monophialide, } \\
5-20 \times 1.5-2.5\end{array}$ & $\begin{array}{l}0-2 \text { septate, } \\
5-29 \times 2-5\end{array}$ & $\begin{array}{l}3-7 \text { septate, } \\
24-65 \times 2.5-5.0\end{array}$ & $\begin{array}{l}\text { Globose to ellipsoidal, } \\
\text { singly or in pairs, } 5-13\end{array}$ \\
\hline F. solani & $\begin{array}{l}\text { Monophialide, } \\
50-110 \times 2.5-3.0\end{array}$ & $\begin{array}{l}0-2 \text { septate, } \\
5-25 \times 2-5\end{array}$ & $\begin{array}{l}3-5 \text { septate } \\
25-44 \times 4-6\end{array}$ & $\begin{array}{l}\text { Globose to oval, } \\
\text { singly or in pairs, } 5-10\end{array}$ \\
\hline F. equiseti & $\begin{array}{l}\text { Monophialide, } \\
2.5-17.5 \times 1.5-2.5\end{array}$ & $\begin{array}{l}0-1 \text { septate, } \\
8-18 \times 2.5-3.8\end{array}$ & $\begin{array}{l}5-7 \text { septate, } \\
38-58 \times 2.5-4.5\end{array}$ & $\begin{array}{l}\text { Globose, singly or } \\
\text { in chains, } 7-13\end{array}$ \\
\hline F. avenaceum & $\begin{array}{l}\text { Monophialide, } \\
6.3-20 \times 2.0-2.5\end{array}$ & $\begin{array}{l}0-2 \text { septate, } \\
5-13 \times 2-3\end{array}$ & $\begin{array}{l}3-7 \text { septate, } \\
33-70 \times 2.5-4.5\end{array}$ & $--^{b}$ \\
\hline F. subglutinans & $\begin{array}{l}\text { Monophialide, } \\
\text { polyphialide, } \\
5-45 \times 2.0-2.5\end{array}$ & $\begin{array}{l}0-2 \text { septate, } \\
5-26 \times 2.0-3.8\end{array}$ & $\begin{array}{l}3-5 \text { septate, } \\
25-48 \times 2.5-3.8\end{array}$ & - \\
\hline
\end{tabular}

${ }^{a}$ Measurement was made after incubation for $15-20$ days on CLA at $27 \%$.

${ }_{-}-$: absent or rarely produced. 

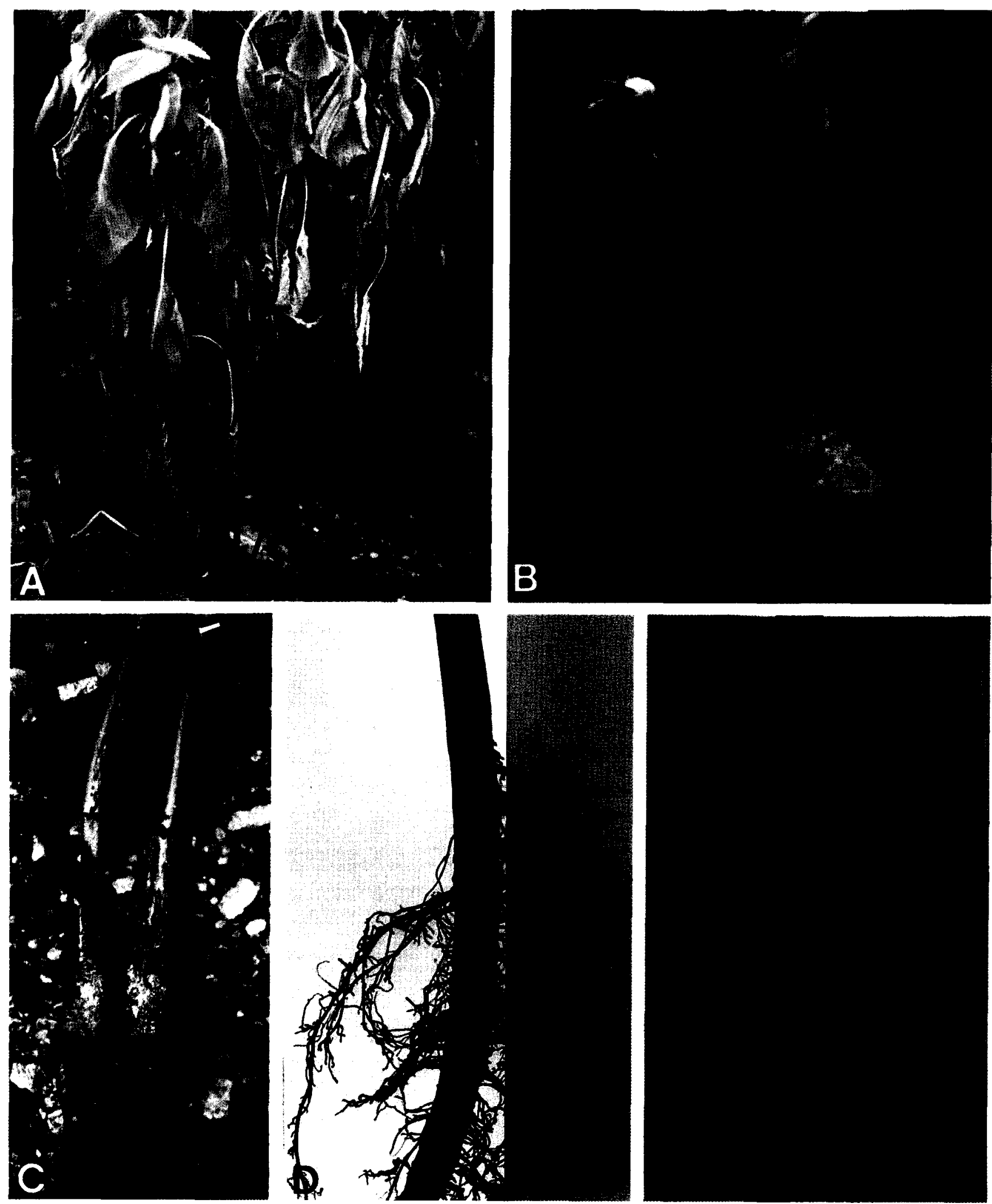

Fig. 1. Symptoms of wilt on perilla plants grown in the fields. (A and B) Wilted plants at the developing or late stage of the disease, respectively; (C and D) Rot of basal parts of stems and roots with black lesions; (E) A longitudinal section of the diseased stem showing discoloration. 


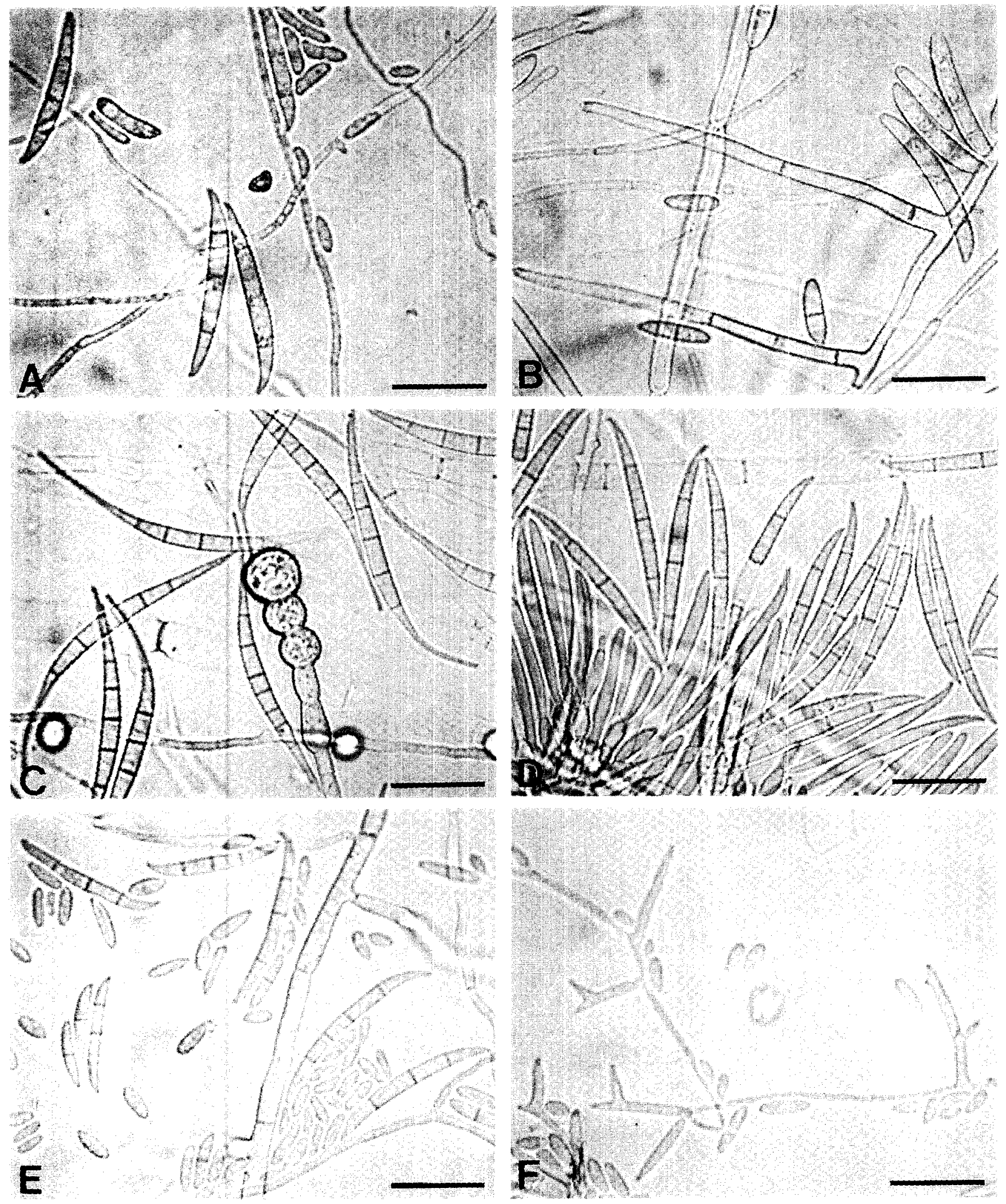

Fig. 2. Morphological features of Fusarium spp. isolated from perilla plants. (A) Microconidia, macroconidia, short monophialides, and hyphae of $F$ oxysportim; (B) Microconidia, macroconidia, long monophialides, and hyphae of $F$ solani; (C) Macroconidia and chlamydospores in a chain and hyphae of $F$ equiseti; (D) Macroconidia, monophialides, and hyphae of $F$. avenaceum; (E and F) Microconidia, macroconidia, mono- and polyphialides, and hyphae of $F$. subglutinans. Each scale bar $\approx 20 \mu \mathrm{m}$. 
Table 3. Isolation and identification of Fusarium spp. from perilla plants showing wilt in the fields

\begin{tabular}{llc}
\hline \hline Species & Location & No. of isolates \\
\hline Fusarium oxysporum & Cheongyang & 22 \\
& Dangjin & 27 \\
& Geumsan & 16 \\
& Hongcheon & 38 \\
& Hwacheon & 9 \\
& Inje & 17 \\
& Namwon & 23 \\
& Sancheong & 15 \\
& Seosan & 38 \\
& Suwon & 10 \\
F. solani & Yangpyeong & 46 \\
& Yeoju & 16 \\
F. equiseti & Hwacheon & 1 \\
& Sancheong & 5 \\
F. avenaceum & Suwon & 5 \\
Fusarium sp. & Cheongyang & 13 \\
& Seosan & 4 \\
Total & Hwacheon & 4 \\
& Cheongyang & 6 \\
& Geumsan & 1 \\
& Sancheong & 3 \\
& Yangpyeong & 4 \\
& Yeoju & 4 \\
\hline
\end{tabular}

comparison with healthy plants. Leaves of diseased plants generally showed discoloration or yellowing with wilt during the mid to late stage of the disease development, then blighted thereafter. Basal parts of stems and roots of diseased plants turned dark-brown to black and rotted in dry condition. The inside parts of the stems turned brown to dark-brown. Severely diseased plants entirely rotted and blighted.

Isolation and identification. A total of 327 isolates of Fusarium spp. were obtained from stems and roots of the diseased perilla plants. The isolates were identified based on their morphological characteristics (Table 2 and Fig. 2). The morphological characteristics of five Fusarium spp. examined by the authors were consistent with those described by previous workers (Booth, 1971; Nelson et al., 1983).

Out of the 327 isolates of Fusarium, 277 isolates obtained from 12 locations were identified as $F$. oxysporum Schlecht.:Fr., 11 isolates from three locations as $F$. solani (Mart.) Sacc., 17 isolates from two locations as $F$. equiseti (Corda) Sacc., 4 isolates from one location as $F$. avenaceum (Fr.) Sacc., and 6 isolates from one location as $F$. subglutinans (Wollenw and Reinking) (Nelson et al., 1983)
(Table 3). The other 12 isolates of Fusarium from four locations were unidentified.

Pathogenicity. Out of the $F$. oxysporum isolates tested, seven isolates were strongly pathogenic to some perilla cultivars, but the other five isolates were weakly or not pathogenic (Table 4). One isolate of $F$. solani was strongly pathogenic to all the perilla cultivars tested, but another one was not pathogenic. All the isolates of $F$. equiseti, $F$. avenaceum, and $F$. subglutinans tested were not pathogenic to the perilla cultivars. Symptoms on the perilla plants induced by artificial inoculation with strongly pathogenic isolates of $F$. oxysporum and $F$. solani appeared as wilt and blight with stem and root rot, which were similar to those observed in the fields. The isolates which induced the symptoms by artificial inoculation were re-isolated from the lesions on the perilla plants inoculated. All the isolates of $F$. oxysporum tested were not pathogenic to eight other crops inoculated (Table 5).

\section{Discussion}

This study is the first report on wilt of perilla caused by Fusarium spp. Five Fusarium spp. were isolated from the diseased perilla plants. Among the Fusarium spp., F. oxysporum and $F$. solani induced wilt symptoms on perilla plants by artificial inoculation, suggesting that the two Fusarium spp. are associated with the disease occurrence in the fields. $F$. oxysporum was the most frequently isolated from the diseased perilla plants, while isolation frequency of $F$. solani and the other Fusarium spp. from the same host plants was very low. This suggests that $F$. oxysporum is the main pathogen of the disease.

Fusarium oxysporum has a wide host range, and many formae speciales of the fungus have been differentiated based on the pathogenicity of the isolates (Armstrong and Armstrong, 1975; Armstrong and Armstrong, 1981; Booth, 1971; Corell, 1991; Kistler, 1997; Snyder and Hansen, 1940). The pattern of diversity for some formae speciales is consistent with a monophyletic clonal population structure (Kistler, 2001). The present study showed that the $F$. oxysporum isolates from diseased perilla plants are host specific to perilla. Consequently, a forma specialis of $F$. oxysporum causing wilt of perilla is proposed as perillae, although pathogenicity tests to other plant species are needed to confirm the host specificity.

It has been reported that several races exist within the isolates of a forma specialis of $F$. oxysporum (Armstrong and Armstrong, 1975; Armstrong and Armstrong, 1981; Kistler, 1997; Stall and Walter, 1965). It was also reported that there are nonpathogenic strains in $F$. oxysporum isolates from plants and soil (Appel and Gordon, 1994; Booth, 1971; Snyder and Hansen, 1940). The present study 
Table 4. Pathogenicity of Fusarium spp. isolates on five cultivars of perilla by artificial inoculation

\begin{tabular}{|c|c|c|c|c|c|c|c|}
\hline \multirow{2}{*}{ Species } & \multirow{2}{*}{ Isolate No. } & \multirow{2}{*}{$\begin{array}{l}\text { Locality of } \\
\text { isolates }\end{array}$} & \multicolumn{5}{|c|}{ Reaction of inoculation tests on cultivars } \\
\hline & & & Areum & Jinmi & Manchu & Saeyeobsil & Yeobsil \\
\hline \multirow[t]{12}{*}{ Fusarium oxysporum } & F6481 & Hwacheon & $t^{\mathrm{a}}$ & - & - & - & - \\
\hline & F6491 & Hongcheon & - & - & + & - & - \\
\hline & F6545 & Inje & + & + & $H$ & - & - \\
\hline & F6578 & Yangpyeong & + & - & + & + & + \\
\hline & F6615 & Yeoju & - & + & + & + & + \\
\hline & F6641 & Dangjin & + & + & + & + & + \\
\hline & F6679 & Seosan & + & + & $H$ & + & + \\
\hline & F6722 & Cheongyang & + & + & $H$ & + & + \\
\hline & F6763 & Geumsan & + & + & + & + & ++ \\
\hline & F6793 & Sancheong & + & + & + & $H$ & $H$ \\
\hline & F6814 & Namwon & + & + & + & + & $H$ \\
\hline & F6852 & Suwon & + & + & + & $H$ & $H$ \\
\hline \multirow[t]{2}{*}{ F. solani } & F6478 & Hwacheon & - & - & - & - & - \\
\hline & F6796 & Sancheong & $+t$ & $H$ & $H$ & + & $H$ \\
\hline \multirow[t]{2}{*}{ F. equiseti } & F6703 & Seosan & - & - & - & - & - \\
\hline & F6726 & Cheongyang & - & - & - & - & - \\
\hline \multirow[t]{2}{*}{ F. avenaceum } & F6471 & Hwacheon & - & - & - & - & - \\
\hline & F6474 & Hwacheon & - & - & - & - & - \\
\hline \multirow[t]{2}{*}{ F. subglutinans } & F6757 & Cheongyang & - & - & - & - & - \\
\hline & F6761 & Cheongyang & - & - & - & - & - \\
\hline Control & & & - & - & - & - & - \\
\hline
\end{tabular}

$++=$ wilted with severe rot of stems and roots; $+=$ not wilted with weak rot of stems and roots; $-=$ no symptom.

Table 5. Pathogenicity of Fusarium oxysporum isolates on eight crops by artificial inoculation

\begin{tabular}{|c|c|c|c|c|c|c|c|c|c|c|c|c|c|c|c|c|}
\hline \multirow{3}{*}{ Isolate No. } & \multicolumn{16}{|c|}{ Reaction of inoculation tests on cultivars of crops } \\
\hline & \multicolumn{2}{|c|}{$\mathrm{Ca}^{\mathrm{a}}$} & \multicolumn{2}{|c|}{$\mathrm{Cu}$} & \multicolumn{2}{|c|}{ Ome } & \multicolumn{2}{|c|}{$\mathrm{Ra}$} & \multicolumn{2}{|c|}{$\mathrm{Se}$} & \multicolumn{2}{|c|}{$\mathrm{Sp}$} & \multicolumn{2}{|c|}{ To } & \multicolumn{2}{|c|}{$\mathrm{Wa}$} \\
\hline & $\mathrm{Gu}^{\mathrm{b}}$ & $\mathrm{Gr}$ & $\mathrm{Ba}$ & $\mathrm{Eu}$ & $\mathrm{Kn}$ & $\mathrm{Ks}$ & $\mathrm{Ha}$ & $\mathrm{Ja}$ & An & Ya & $\mathrm{Gu}$ & $\mathrm{Pa}$ & $\mathrm{Se}$ & $\mathrm{Gw}$ & Bo & $\mathrm{Da}$ \\
\hline F6481 & $-^{c}$ & - & - & - & - & - & - & - & - & - & - & - & - & - & - & - \\
\hline F6491 & - & - & - & - & - & - & - & - & - & - & - & - & - & - & - & - \\
\hline F6545 & - & - & - & - & - & - & - & - & - & - & - & - & - & - & - & - \\
\hline F6578 & - & - & - & - & - & - & - & - & - & - & - & - & - & - & - & - \\
\hline F6615 & - & - & - & - & - & - & - & - & - & - & - & - & - & - & - & - \\
\hline F6641 & - & - & - & - & - & - & - & - & - & - & - & - & - & - & - & - \\
\hline F6679 & - & - & - & - & - & - & - & - & - & - & - & - & - & - & - & - \\
\hline F6722 & - & - & - & - & - & - & - & - & - & - & - & - & - & - & - & - \\
\hline F6763 & - & - & - & - & - & - & - & - & - & - & - & - & - & - & - & - \\
\hline F6793 & - & - & - & - & - & - & - & - & - & - & - & - & - & - & - & - \\
\hline F6814 & - & - & - & - & - & - & - & - & - & - & - & - & - & - & - & - \\
\hline F6852 & - & - & - & - & - & - & - & - & - & - & - & - & - & - & - & - \\
\hline Control & - & - & - & - & - & - & - & - & - & - & - & - & - & - & - & - \\
\hline
\end{tabular}

${ }^{\mathrm{a}} \mathrm{Ca}=\mathrm{cabbage} ; \mathrm{Cu}=$ cucumber; Ome=oriental melon; $\mathrm{Ra}=$-radish; $\mathrm{Se}=$ sesame; $\mathrm{Sp}=$ spinach; $\mathrm{To}=$ tomato; $\mathrm{Wa}=$ watermelon.

${ }^{\mathrm{b}} \mathrm{Gu}=\mathrm{Gusto} ; \mathrm{Gr}=\mathrm{Green}$ Hero; $\mathrm{Ba}=$ Baekrokdadagi; Eu=Eunseongbaekdadagi; Kn=Keumnodajieuncheon; Ks=Keumssragieuncheon; Ha= Hanoldaehyeong; Ja=Jangchundaehyung; $\mathrm{An}=\mathrm{Ansan}$; Ya=Yangbaek; $\mathrm{Gu}=\mathrm{Guibin} ; \mathrm{Pa}=\mathrm{Paroogu} ; \mathrm{Se}=\mathrm{Seogwang}$; $\mathrm{Gw}=\mathrm{Gwangmyeong}$; $\mathrm{Bo}=\mathrm{Bok}-$ soobak; $\mathrm{Da}=\mathrm{Dalsoobak}$

$c_{-}=$no symptom.

revealed that there are differences in pathogenicity among the $F$. oxysporum isolates from diseased perilla plants, and that some isolates are not pathogenic to some cultivars of perilla. The results suggest that virulence of the pathogenic 
isolates of $F$. oxysporum differs depending on the perilla cultivars. Further study is needed to classify the races of the pathogenic isolates of $F$ oxysporum.

\section{References}

Anonymous. 1998. List of Plant Diseases in Korea. 3rd edition. Korean Soc. Plant Pathol., Korea. 436 p.

Appel, D. J. and Gordon, T. R. 1994. Local and regional variation in populations of Fusarium oxysporum from agricultural field soils. Phytopathology 84:786-791.

Armstrong, G. M. and Armstrong, J. K. 1975. Reflections on the wilt fusaria. Annu. Rev. Phytopathol. 13:95-103.

Armstrong, G. M. and Armstrong, J. K. 1981. Formae speciales and races of Fusarium oxysporum causing wilt diseases. In: Fusarium: Diseases, Biology and Taxonomy, ed. by P. E. Nelson, T. A. Toussoun, and R. J. Cook, pp. 391-399. The Pennsylvania State University Press, University Park, USA.

Booth, C. 1971. The Genus Fusarium. Commonwealth Mycological Institute. Kew, Surrey, England. 237 p.

Correll, J. C. 1991. The relationship between forma specialis, races, and vegetative compatibility groups in Fusarium oxysporum. Phytopathology 81:1061-1064.

Fisher, N. L., Burgess, L. W., Toussoun, T. A. and Nelson, P. E. 1982. Carnation leaves as a substrate and for preserving cultures of Fusarium species. Phytopathology 72:151-153.

Kistler, H. C. 1997. Genetic diversity in the plant-pathogenic fungus Fusarium oxysporum. Phytopathology 87:474-479.

Kistler, H. C. 2001. Evolution of host specificity in Fusarium oxysporum. In: Fusarium: Paul E. Nelson Memorial Symposium, ed. by B. A. Summerell, J. F. Leslie, D. Backhouse, W. L. Bryden, and L. W. Burgess, pp. 70-82. APS Press. The Amer. Phytopath. Soc., St. Paul, MN, USA.

Nelson, P. E., Toussoun, T. A. and Marasas, W. F. O. 1983. Fusarium Species: An Illustrated Manual for Identification. The Pennsylvania State University Press, University Park, USA. 193 pp.

Snyder, W. C. and Hansen, H. N. 1940. The species concept in Fusarium. Amer. J. Bot. 27:64-67.

Stall,'R. E. and Walter, J. M. 1965. Selection and inheritance of resistance in tomato to isolates of races 1 and 2 of the Fusarium wilt organism. Phytopathology 55:1213-1215. 